\title{
REENCENAÇÃO E PÓS-APOCALIPSE NA OBRA FOTOGRÁFICA DE FRANCESCA WOODMAN
}

\author{
BRANCO, Luís Carlos $\mathrm{S}^{1}$
}

\begin{abstract}
RESUMO: A obra fotográfica de Francesca Woodman surge integrada numa geração estadunidense de fotógrafas, ainda imbuídas do espírito da segunda vaga feminista, nos anos setenta, da qual fazem parte Ana Mendieta e Cindy Sherman, entre outras. Para além da evidente qualidade estética, a obra de Woodman é profundamente questionadora dos papéis de gênero, que tende a inverter e a rasurar nas suas fotografias sempre de modo pertinente. Neste sentido, são particularmente significativos os seus tableaux vivants fotográficos, nos quais recria quadros célebres do cânone artístico mundial e de passagens bíblicas, questionando assim, nas suas recriações, não só as noções de gênero, mas também a própria validade da historiografia artística oficial, dominada pelo ponto de vista masculino. Simultaneamente, as suas fotografias configuram um mundo pós-apocalíptico e propõem uma utopia de índole feminista como resposta. Pretendo analisar com detalhe os elementos referidos.
\end{abstract}

PALAVRAS-CHAVE: Francesca Woodman, anos 70, Utopia Feminina, Pós-apocalipse, Tableaux Vivants,

\section{RESTAGING AND POST-APOCALYPSE IN FRANCESCA WOODMAN'S PHOTOGRAPHIC WORK}

\begin{abstract}
Francesca Woodman's photographic work is part of an American generation of photographers that created during the seventies which includes Ana Mendieta and Cindy Sherman, among others. They were all still imbued with the spirit of the second feminist. Besides the obvious astonishing aesthetic quality, Woodman's work is deeply questioning of
\end{abstract}

\footnotetext{
${ }^{1}$ Pesquisador, Departamento de Línguas e Culturas/ Centro de Línguas, Literaturas e Culturas da Universidade de Aveiro, Portugal. Endereço Eletrónico: lcrsb@ua.pt

Jangada | nr. 14, jul/dez, 2019 | ISSN 2317-4722

39 | P á g i n a
} 
gender roles, which she always tends to reverse and erase in her photographs in a very intelligent way. Thus, her Tableaux Vivants are, at this light, particularly significant. In them, she recreates famous paintings of the world artistic canon and biblical passages, questioning the notions of gender and the validity of official artistic historiography, which is mainly dominated by a masculine point of view. At the same time, her photographs shape a post-apocalyptic world and propose a feminist utopia in response. I intend to analyze all these elements.

KEYWORDS: Francesca Woodman, 1970s, Women Utopia, Post-apocalypse, Tableaux Vivants.

1. Francesca Woodman passou muito rapidamente pela vida que deu por finda em 19 de janeiro de 1981, atirando-se de uma janela no East Side, em Nova Iorque (WILLIS, 2010). Atrás de si, e tendo em consideração os seus vinte e dois anos, deixou uma obra de grande maturidade artística, constituída por cerca de seiscentas fotografias, mais de dez mil negativos, alguns vídeos (WOODMAN, 1976-1981) e sete cadernos de artista, dos quais apenas um foi dado a lume em vida da autora (WOODMAN, 1981). Parte deste precioso acervo continua por publicar. Os pais da fotógrafa têm gerido o seu espólio, dando a conhecer, espaçada e estrategicamente, trabalhos inéditos com o intuito de consolidar a reputação artística de Francesca e de manter nos opinion makers do mercado de arte internacional um interesse permanente pela obra da filha.

As mais variadas e reputadas instituições têm exposto regularmente o trabalho de Woodman e têm adquirido obras dela. A saber, e entre tantas outras: a Hunter College Art Gallery (a primeira a fazer uma retrospetiva a título póstumo, em 1986), a Victoria Miro Gallery em Londres, a Kamel Mennour em Paris e o Centro Cultural de Belém, que, em 1999, expôs trabalhos da artista. Eduardo Prado Coelho analisou entusiasticamente esta exposição de Woodman:

Vi o trabalho de Francesca Woodman pela primeira vez na Fundação Cartier Bresson, em Paris como uma espécie de descoberta. Quando descobrimos uma obra como a de Francesca Woodman podemos ter com ela uma relação de paixão. Paixão a posteriori, paixão que já passou, mas que continua a ser 
paixão. Paixão por alguém que não conhecemos e que tentamos reconhecer através destas imagens. (COELHO, 1999) ${ }^{2}$

Quem mais tem beneficiado com o estatuto e difusão que, entretanto, a obra de Woodman ganhou, têm sido as fotógrafas das novíssimas gerações que a referem como primacial influência e que reclamam para si o seu legado artístico. Jovens criadores de várias áreas dialogam intertextualmente com a sua seminal produção artística. A poetisa Ariana Reines, o escritor Phillippe Sollers e a artista plástica brasileira Adriana Varejão, entre outros, referem-na (SOLOMON-GODEAU, 2014).

2. Francesca Woodman fez parte da combativa geração de fotógrafas que emergiu nos anos setenta e início dos anos oitenta do século passado com preocupações e topoi transversais a todas, designadamente as questões de gênero e a ambição de firmarem o seu nome no mercado da arte (RICHES, 2004, p. 14-35). O movimento feminista estava em plena expansão em várias áreas do saber humano e o, à época, controverso ideário propalado por Simone de Beauvoiur e Betty Friedan estava na ordem do dia e também, já por essa altura, Camille Paglia trabalhava na sua polêmica proposta do paganismo sexual, Judith Butler começava as investigações para a sua tese de doutoramento e o seu subsequente redesenhar das questões de gênero e Wendy MacElroy preparava as suas propostas de um feminismo centrado na individualidade e mais consentâneo com os novos papéis sociais da mulher na sociedade ocidental das décadas de setenta e oitenta. Existem, assim, multímodos paralelismos entre a obra de Woodman e das suas coetâneas companheiras de rota.

Em um nível meramente formal, podemos assinalar várias confluências de teor estilístico no trabalho destas fotógrafas. Por exemplo: as representações, usualmente de motu proprio, do nu feminino, a insistência no autorretrato, o uso de utensílios com conotações culturais remetentes para o universo feminino, joias, facas, garfos, panelas e roupa. A utilização destes adereços, por parte destas artistas, está longe de ser inocente. São objetos com um significado simbólico evidente. A este propósito, atente-se na seguinte elucidação de Beauvoir sobre a condição feminina:

À mulher, para que realize a feminilidade, pede-se que se faça objeto e presa, isto é, que renuncie às suas reivindicações de sujeito soberano. É esse conflito

\footnotetext{
${ }^{2} \mathrm{~A}$ transcrição desta análise feita coloquialmente por Eduardo Prado Coelho é da minha responsabilidade. Jangada | nr. 14, jul/dez, 2019 | ISSN 2317-4722 
que carateriza singularmente a situação da mulher libertada. Ela recusa confinar-se no seu papel de fêmea porque não quer mutilar-se, mas repudiar o sexo seria também uma mutilação. O homem é um ser humano sexuado: a mulher só é um indivíduo completo, e igual ao homem, sendo também um ser sexuado. Renunciar à sua feminilidade é renunciar a uma parte da sua humanidade. (BEAUVOIR, 2015, p. 536)

Sobre Woodman, Riches esclarece que:

Woodman's own exploration and manipulation of domestic confinement also makes use of similar set of motifs and concerns common to women artists who were working in the context of 1970s art practice. Reawakened by the feminist movement, the theme of domesticy came to dominate artistic production by politically engaged female artists at the time. (RICHES, 2004, p. 49-50) ${ }^{3}$

Os elementos formais, atrás referidos, podem facilmente ser encontrados nas obras de Hannah Wilke, Birgit Jürgensen, Diane Arbus e Cindy Sherman, entre outras. A latinoamericana Ana Mendieta - com quem, para lá de um final de vida similar por defenestração, Francesca Woodman partilha várias preocupações isotópicas - produziu uma série de fotografias nas quais posa nua com um vidro quadrado que encosta com violência sobre os seios, rosto e lábios. Coincidentemente, Woodman usa como adereço um vidro quadrado com o qual empurra os seios e o sexo. Por seu lado, Jürgensen usa máscaras representando a morte, mormente caveiras, com as quais joga com a nudez do seu corpo; Woodman, de modo similar, produziu uma fotografia na qual podemos ver uma sinistra máscara branca masculina tapandolhe o sexo.

\footnotetext{
${ }^{3}$ Todas as retroversões de Inglês para Português, presentes em notas de rodapé, são da minha autoria. A tradução do excerto supra é a seguinte. "A exploração e manipulação artística que Francesca Woodman faz do confinamento em ambiente doméstico reflete preocupações comuns à sua geração artística e usa a mesma panóplia de leitmotive partilhados pelas outras artistas que estavam a trabalhar no contexto das práticas artísticas dos anos 70 . Em grande parte, devido ao movimento feminista, o tema da domesticidade ganhou um novo fôlego e veio a tornar-se dominante nas produções artísticas das artistas politicamente empenhadas dessa época." (RICHES, 2004, p. 4950).
}

Jangada | nr. 14, jul/dez, 2019 | ISSN 2317-4722 42 | P á g i n a 
Estas insignes fotógrafas estavam, à época, a iniciar as suas carreiras e muito provavelmente não conheciam o trabalho umas das outras. As coincidências processuais e imagéticas são, portanto, explicáveis à luz de preocupações artístico-filosóficas comuns, já brevemente afloradas em cima. $\mathrm{Na}$ verdade, todas elas puseram em causa as representações do feminino na sociedade e na História da Arte, bem como questionaram fortemente, nas suas obras, os lugares de enunciação, mediação e receção dos lugares de gênero.

3. Não só ao longo da história, mas também na cultura pop, por essa altura em plena ebulição, as representações do corpo feminino eram, na sua esmagadora maioria, criadas para o olhar masculino. Por isso, quando Ana Mendieta parece esmagar os seios contra o vidro ou encosta os lábios perigosamente contra essa superfície aguçada, aludindo assim ao flagelo da violência doméstica, ou quando Francesca Woodman, por seu turno, numa pose coquette expõe o corpo nu com um olhar sedutor e simultaneamente usa ao pescoço animais empalhados ou coloca os seios defronte de pedaços de melões despedaçados, é como se esse olhar, esse male gaze, fosse devolvido em carne viva ao enunciador. Estamos, portanto, nos antípodas das fotografias onanistas criadas, por exemplo, por Jody Frost ou Lisa Boyle.

Berger, que analisou as representações de género ao longo do tempo na arte, sobre o uso do nu, explica:

One might simplify this by saying: men act and women appear. Men look at women. Women watch themselves being looked at. This determines not only most relations between men and women but also the relation of women to themselves. The surveyor of woman in herself is male: the surveyed female. Thus, she turns herself into an object - and most particularly an object of vision: a sight. (BERGER, 1990, p. 47)

\footnotetext{
4 "De modo necessariamente simplista, poderíamos dizer que os homens agem e as mulheres aparecem. Os homens olham para as mulheres. As mulheres olham para si mesmas enquanto são observadas. E isto determina, não apenas a maioria das relações entre homens e mulheres, mas a relação das mulheres com elas mesmas. $\mathrm{O}$ inspetor da mulher dentro dela mesma é masculino: a mulher inspecionada. Ela transforma-se assim a si própria em objeto mais concretamente, ela auto-transforma-se num objeto de visão; numa aparição.” (BERGER, 1990, p. 47).
} 
Por isso mesmo, no trabalho fotográfico da geração de artistas na qual Francesca Woodman se inclui, nada é produzido para excitar o olhar masculino, e, desse modo, perpetuar o male gaze. Muito pelo contrário, são fotografias que remetem para a reflexão sobre esse próprio olhar. Quem as contempla dá forçosamente por si a interrogar-se afinal como e porque olha. É por demais evidente a sua carga ideológico-libertária.

Embora sem caráter derrisório, é nítido também o recurso ao grotesco por parte destas fotógrafas no modo como se autorrepresentam. O uso de máscaras rituais por Jürgensen, de animais empalhados por Woodman, de sangue humano por parte de Mendieta, ou a preferência por casas abandonadas e pântanos lamacentos como cenários das suas fotografias configura uma representação grotesca do corpo feminino - avessa, portanto, ao male gaze.

Estas estrênuas artistas podiam ter enveredado por um caminho mais fácil de trilhar. Sublinhe-se que, senão para todas, pelo menos para a grande maioria delas, o êxito surgiu tardiamente. Cindy Sherman começou a tornar-se relevante apenas nos últimos anos da década de oitenta e a Francesca Woodman só postumamente lhe foi reconhecido o devido valor artístico, sobretudo, como já referi, a partir da sua primeira retrospetiva a título póstumo, em 1986, ganhando depois o estatuto de artista relevante a uma escala mundial (WILLIS, 2010).

Poder-se-á contrapor que não será tanto assim, pois, apesar disso, quase todas conseguiram dar a conhecer o seu trabalho na década de 70 e nunca foram impedidas de fazer exposições, o que é, sem dúvida, verdade; mas é igualmente inegável que pouca ou nenhuma atenção lhes foi dispensada quer pela crítica, quer pelos agentes do mercado de arte da época. Por exemplo, em relação a Woodman, apenas Max Kozloff manifestou algum entusiamo crítico pela sua obra, e sobre a sua primeira exposição apenas uma articulista, Edith Schloss, da revista International Herald Tribune, lhe dedicou algumas linhas:

And she expresses the evanescent and movement in consistent and usually evocative small images which travel beyond ordinary photography. At times she uses her own nude body - jumping, curling up or just pigeon-footedly standing next to eels or other slithering things - but without a trace of 
eroticism or narcissism. All the photographs are fresh. (apud SCHOR; BRONFEN, 2014, p. 297) $)^{5}$

Só a partir dos últimos anos da década de oitenta e nos anos noventa é que estas fotógrafas conseguiram, de facto, obter rendimentos suficientes para poderem custear a sua vocação artística. Algumas delas, menos resilientes, desapareceram antes de atingirem esse patamar, caso de Mendieta e Woodman. O pai de Francesca, George Woodman, aponta como uma das razões que, em larga medida, terá contribuído para o suicídio da filha, a falta de reconhecimento do seu trabalho artístico, aduzindo a inexplicável não conceção de uma bolsa de criação por parte do National Endowment for The Arts, instituição à qual Francesca tinha concorrido, numa altura em que se debatia com sérios problemas de índole econômica. Segundo o testemunho do pai, ela soube desta recusa no mesmo dia em que deu o fatídico salto (WILLIS, 2010).

Ela enviou também o seu portfólio para vários lugares onde se praticava fotografia de moda; contudo, e apesar de ter sido uma aluna de exceção na Rhode Island School of Design e de ter já no seu currículo algumas exposições quer individuais, quer coletivas, foi sucessiva e categoricamente recusada, sendo-lhe oferecido apenas lugares secundários como segunda ou terceira assistente de fotografia (WILLIS, 2010). Viu-se assim obrigada a trabalhar como secretária e como modelo de nus.

4. Como já referi, a obra de Francesca Woodman teve uma assinalável fortuna crítica a título póstumo e um dos fatores que, sem dúvida, terá contribuído para isso é o seu caráter ambíguo, o fato de ela não escamotear nunca a presença avassaladora do desejo passional - sublinhe-se, portanto, que as questões de gênero surgem no seu trabalho a partir das suas vivências íntimas. Estamos a falar duma obra profundamente autognóstica.

Esclareça-se desde já que algumas interpretações críticas que acentuavam artificialmente a tónica político-feminista do trabalho de Woodman estão hoje ultrapassadas e têm sido alvo das mais variadas revisões críticas, como é o caso flagrante de Abigail Solomon-

\footnotetext{
5 "Ela expressa o movimento e a evanescência em fotografias consistentes e evocativas, de pequena dimensão, que vão muito para além de uma mera arte fotográfica vulgar. Por vezes, usa o seu próprio corpo nu - saltando, enroscando-se ou posando com o corpo contorcido perto de enguias ou de outros adereços com textura escorregadia - mas sem o mínimo indício de erotismo ou narcisismo. Todas as fotografias revelam frescura." (apud SCHOR; BRONFEN, 2014, p. 297).
}

Jangada | nr. 14, jul/dez, 2019 | ISSN 2317-4722 45 | P á g in a 
Godeau (SOLOMON-GODEAU, 1986) que teve um importante papel crítico pioneiro e que foi uma das primeiras pessoas a apontar a questão do doppelganger e do fetichismo na obra de Woodman, mas cuja leitura algo enviesada da obra dessa fotógrafa, à luz de um feminismo militante, veio a provar-se datada e um pouco forçada (RICHES, 2004, p. 22). Vejamos: a dimensão feminista de Woodman decorre, emerge, de modo natural do seu trabalho e não o oposto. Betsy Berne que privou com ela e que fez parte da mesma geração artística feminina em Nova Iorque, e que é hoje uma artista e escritora consagrada, é claríssima acerca do modo como devemos situar a questão feminista no trabalho de Woodman:

And then there was the "feminist" question: to be or not to be. The truth is, it was a moot point, or rather a moot question. We were at the very beginning of a generation who were feminists as a matter of course, we were ungrateful wretches who took it for granted. (...) There was no need to discuss it or to parade feminist theory in obvious self-conscious visuals. Francesca was simply doing her work, and hopefully it would provoque and tease, raise questions and suggest answers, and reflect ambivalence about being a woman and much more than that. (BERNE, 2014, p. 91$)^{6}$

5. As fotografias de Woodman são pródigas na convocação de elementos muito concretos, como é o caso de árvores, portas, peixes, garfos, cortinas, lareiras, mas são também repletas de elementos fantasmáticos: sombras, corpos desfocados, ruínas, sangue, rostos elididos, fragmentos e escombros da mais diversa índole, desde janelas partidas a pedaços de pedra e papel rasgado. O seu universo fotográfico configura um mundo pós-apocalíptico. As suas fotografias são retratos pós-catástrofe. Neste sentido, Raymond, recorrendo a Blanchot e às memórias do holocausto, diz o seguinte:

\footnotetext{
6 "Havia também a questão "feminista": ser ou não ser. A verdade é que esta era uma questão quase irrelevante para nós. Nós estávamos no início de uma geração de mulheres que eram feministas por isso ser algo natural e lógico. Se calhar, éramos ingratas miseráveis que encaravam estas questões como um dado adquirido. (...) Não sentíamos necessidade nenhuma de sermos panfletárias ou de exibirmos o nosso feminismo. A Francesca estava simplesmente a fazer o seu trabalho o melhor que sabia, esperando que ele, por si mesmo, levantasse questões, provocasse dúvidas e sugerisse respostas, refletindo a ambivalência inerente à condição feminina, mas que também conseguisse chegar mais longe do que isso.” (BERNE, 2014, p. 91).
} 
The knowledge, then, of the holocaust works its way into the twentiethcentury aesthetics. Woodman, who is not directly responding to the war, yet reflects in her work a deep engagement with the core of nothingness, suggested by postwar shifts in aesthetics and philosophy. (RAYMOND, 2016, p. 17) ${ }^{7}$

O contraponto a este cenário de pós-apocalipse e ruínas presente na obra da fotógrafa é a presença vitalista do desejo. Tudo poderá eventualmente parecer ausente e distante no trabalho artístico de Woodman, com exceção do desejo. Aliás, neste contraste dialógico entre a devastação pós-apocalíptica e as figurações de uma libido vulcânica se joga, em um duelo íntimo, a sua obra. Por isso, a fotógrafa se autorrepresenta, muitas vezes, como uma sobrevivente. Uma sobrevivente envolta nas contradições passionais em um mundo onde, talvez, o desejo esteja destinado a tornar-se, também ele, ruínas e pó.

Um dos estilemas imagéticos mais usados por ela é o fora-de-campo. Deleuze, que concedeu ao fora-de-campo uma grande atenção teórica, diz-nos o seguinte: "Ora o fora-decampo remete para um espaço visual, de direito, que prolonga naturalmente o espaço visto na imagem (...) o fora-de-campo revela um poder de outra natureza que excede todo o espaço e todo o conjunto.” (DELEUZE, 2015, p. 368). Podemos verificar na obra de Woodman uma proliferação constante de presenças fora-de-campo de todo o tipo. Por exemplo, portas, paredes e janelas das quais raramente se percebe a sua localização exata e o que lá se passa. Numa delas, percebemos que a fonte de luz paradoxalmente é uma janela que está envolta na mais completa escuridão. Um dos traços narrativo-diegéticos do pós-apocalíptico é o fato de as fontes causadoras do apocalipse mostrarem a sua presença, mas nunca se darem, de fato, a ver (HEFFERNAN, 2008). Este gênero de presenças invisíveis pulula as fotografias de Woodman. Riches refere que:

\footnotetext{
7 “A tomada de conhecimento do holocausto teve amplas consequências nas estéticas do século XX. Francesca Woodman, apesar de não estar a confrontar isso, de modo direto, no seu trabalho fotográfico, no entanto, não lhe é indiferente, e é visível nela um comprometimento profundo com a rarefação, com a sinalização do nada, preconizada pelos movimentos estéticos e filosóficos do pós Segunda Guerra Mundial." (RAYMOND, 2016, p. 17).
}

Jangada | nr. 14, jul/dez, 2019 | ISSN 2317-4722

47 | P á g in a 
Punctured by moments of absence - or self-absenting - the possibilities of any narrative flows is fractured by her fluctuating presence, which highlights the internal gaps and seams. Drawing attention to the limits of the still photograph. Woodman's displacement also draws attention to the condition of the framing edge, suggesting that in a process of self-representation, the subject is always just out of shot." (RICHES, 2004, p. 143) ${ }^{8}$

O fetichismo também emerge na sua obra - naquilo que Solomon-Godeau designa por "theater of the fetish", teatro do fetiche, (SOLOMON-GODEAU, 1986) - porém, não como espaço de negação ou asserção, mas antes como problemática reificada.

A sua amiga, colega da Rhode Islands School of Design, já antes citada, Betsy Berne, confidencia-nos que Francesca Woodman, ao contrário de muitos dos jovens artistas que se encontravam, tal como ela, naquela época a tentar a sua sorte nos meandros artísticos de Nova Iorque, não tomava drogas nem bebia, no entanto, vivia sempre entre dois polos antitéticos: o mais restrito puritanismo e o hedonismo mais desbragado (BERNE, 2014, p. 92). Esta arriscada viagem entre estes dois vértices está bem documentada na sua obra, e, de certo modo, consigna o desejo em declinação apocalíptica. Berger explica a dualidade apocalíptica nos seguintes termos: "This combination of violent hatred for the world as it is and violent desire for the world has it should be has characterized apocalyptic representations (...) since their first recorded instances" (BERGER, 1999, p. 34). ${ }^{9}$ Este autor refere igualmente que o desejo apocalíptico é um desejo por um final, mas também um desejo pelo que surgirá depois. Assim, nas fotografias em cenário pós-apocalíptico de Woodman, há uma demanda constante por um apaziguamento que, na verdade, não chegou nunca a ser encontrado pela malograda fotógrafa.

6. Os pais dela, George e Betty Woodman, eram artistas plásticos, o seu irmão é hoje Professor de Arte Eletrônica. Francesca Woodman nasceu, portanto, num ambiente propício ao seu precoce desenvolvimento artístico (WILLIS, 2010).

\footnotetext{
8 "Pontuada por momentos de ausência - ou auto-ausência - a possibilidade de que qualquer narrativa possa fluir é interrompida pela presença errática de Woodman, que acentua os buracos e costuras interiores da imagem, convocando, deste modo, a nossa atenção para os limites intrínsecos da própria fotografia. A sua deslocalização sublinha também os limites da moldura, sugerindo, de algum modo, que num processo de autorrepresentação o sujeito está sempre fora-de-campo, sempre para lá da própria fotografia.” (RICHES, 2004, p. 143).

9 "Esta combinação de ódio violento ao mundo, tal como ele é, e de desejo brutal pelo mundo, tal como ele deveria ser, tem, desde sempre, caraterizado as representações apocalípticas". (BERGER, 1999, p. 34).
}

Jangada | nr. 14, jul/dez, 2019 | ISSN 2317-4722 48 | P á g in a 


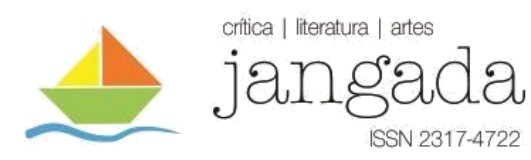

Em grande medida devido ao seu apreço pela arte italiana, os pais batizaram-na com um nome de origem italiana: Francesca. Ela foi exposta a dois tipos de cultura com princípios antagônicos: uma cultura estadunidense puritana e uma cultura romana mais livre e mais dada aos prazeres dos sentidos - este conflito marcou a ferro quente toda a sua obra. Eduardo Prado Coelho salientou que esta dualidade está patente no próprio nome da artista: o sedutor e italiano "Francesca" e o americano e rígido "Woodman" (COELHO, 1999)

Os pais passavam longas temporadas em Itália e, por isso, ela frequentou uma escola pública em Florença, em 1965, aprendendo a ler e a escrever em italiano, tornando-se bilingue (WILLIS, 2010). Mais tarde, em 1977, devido a uma bolsa que o Rhode Islands Institute of Design concedia aos seus alunos do quadro de honra, viveu em Roma durante um ano, onde conheceu vários jovens criadores italianos, como Giuseppe Gallo e Angelo Segneri, frequentadores da Livraria Maldoror, especializada, como o próprio nome indica, em literatura de cariz maldito. Os pais eram assíduos frequentadores de exposições, levando com eles os seus dois filhos (WILLIS, 2010). Numa fotografia de família tirada pelo pai, podemos vê-la, ainda criança, sentada defronte dum quadro, tentando reproduzi-lo no seu caderno de desenhos (SCHOR; BRONFEN, 2014, p. 266).

Teve aulas de piano durante alguns anos, mas abandonou-as a favor da fotografia. Aos treze anos ocorreu a grande descoberta ao tomar contacto com a arte fotográfica e descobrir assim a sua vocação artística e o seu medium de eleição. Transformou imediatamente o seu quarto num estúdio e passou a dormir num armário, passando o tempo a fotografar e a revelar as fotografias. Estudou obsessivamente a história e os mecanismos desta arte. Começou a fotografar-se incessantemente a si mesma num exercício eminentemente exploratório (WILLIS, 2010). Data desta época epifânica uma fotografia, tirada aos treze anos, na qual a vemos sentada e vestida, com os cabelos tapando o rosto por completo e a sua mão esquerda imiscuindo-se em um fio de luz vindo não sabemos de onde (SCHOR; BRONFEN, 2014, p. 99).

Não era grande apreciadora de música Pop-Rock nem de televisão, ambas em pleno período áureo; ao invés, foi sempre uma leitora compulsiva (RICHES, 2004, p. 14). Francesca amava, em especial, a obra de Marcel Proust, Em Busca do Tempo Perdido, que leu e releu diversas vezes e que a acompanhava para todo o lado. Uma das suas séries fotográfica cita precisamente o segundo volume desta obra, intitulado Do Lado de Swann. A própria artista asseverou: "Proust inspired me a lot. I'd really like to create a work of art like that, rooted in 


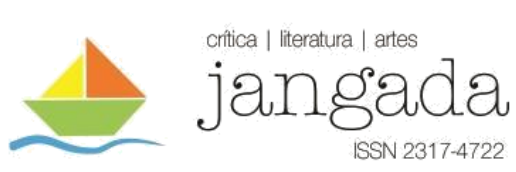

and linked to everyday life, but addressing questions of great scope" (apud SCHOR, 2014a, p. 33). ${ }^{10}$

As suas fotografias podem ser descritas como peças teatrais em um ato. Schor refere que as fotografias de Woodman encenam "the mysterious theatrical presentation of the female body", a representação teatral misteriosa do corpo feminino (SCHOR; BRONFEN, p. 7). Cada foto sua, na verdade, funciona como um capítulo narrativo que se encaixa romanescamente em um todo maior. Cada imagem, portanto, faz parte de uma série e cada série termina onde a seguinte parece começar. Para além das referências literárias per se, este encaixe narrativo das fotografias sequencialmente umas nas outras remete para o pós-apocalíptico. Pippin esclarece que "Every apocalypse is a sequel. A sequel is a work which follows another work and can be complete in itself and seen in relation to the former and also what follows it. The story becomes the never-ending story in ever-evolving renditions" (PIPPIN, 1999, p.1). ${ }^{11}$ Nesta mesma linha de pensamento, Berger também nos diz que nas representações apocalípticas não há nunca um final. Existe uma contínua liminaridade (BERGER, 1999). Este continuum pós-apocalíptico é, sem dúvida, o cenário preferencial da obra fotográfica de Woodman.

É, portanto, observável uma linha de evolução no trabalho de Woodman, mas, sublinhese, sempre enquadrada num cenário pós-apocalíptico que, desde o início, a artista concebeu e que nunca mais abandonou. E, neste palco de ruínas, de devastação, encenado pela fotógrafa, um dos elementos mais importantes é o seu próprio corpo: a sua nudez pós-apocalíptica. Esta não é nunca um elemento estranho neste quadro de pós-catástrofe, ao invés, ainda que o interrogue, integra-se visceralmente nele.

7. Quando da sua estadia em Roma, ela pôde estudar in loco alguns dos artistas renascentistas de quem se sentia próxima. O já referido Giuseppe Gallo, artista que privou com ela em Roma, afiança-nos que "She knew all the sixteenth-century painters very well", que ela conhecia muito bem as obras dos pintores do seculo XVI, (apud SCHOR, 2014a, p. 45). Woodman viu e estudou com especial interesse obras de Miguel Ângelo Buonarroti e Caravaggio de quem admirava o arrojo temático e a inovação formal. Ambos eram magníficos retratistas e, tal como

\footnotetext{
10 "Proust inspirou-me imenso. Eu gostaria muito de criar um trabalho de arte como o dele, que nos remete para questões de grande alcance, mas enraizado na vida quotidiana." (apud SCHOR, 2014a, p. 33).

11 "Todo o apocalipse é uma sequela. Uma sequela é um trabalho que se segue a outro trabalho e que pode ser completo em si mesmo, ou ser visto em correlação com o que o antecede e com o que se lhe seguirá. A narrativa torna-se, deste modo, infinita, numa relação dialógica interminável.” (PIPPIN, 1999, p. 1).
}

Jangada | nr. 14, jul/dez, 2019 | ISSN 2317-4722 50 | P á g i n a 


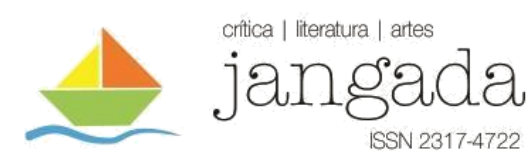

ela própria, estavam interessados em explorar até aos limites a figuração humana. O amplo conhecimento do cânone artístico por parte da fotógrafa foi utilizado com muito proveito na sua própria obra. A intertextualidade imagética é um elemento absolutamente nodal nas suas fotografias. Muitos processos estilísticos caraterísticos da pintura foram transpostos por ela para o seu trabalho fotográfico. Pululam, por isso, na sua obra, as naturezas-mortas, o uso, com evidentes funções poéticas, de todo o tipo de adereços e a insistência obsessiva no autorretrato (SCHOR, 2014 a, p. 49).

No contexto das questões de género, é particularmente revelador o uso que ela fez dos tableaux vivants: a recriação nas suas fotografias de quadros famosos onde ela própria figura como modelo (BRONFEN, 2014, p. 11-30). Sobre este tópico, Claire Raymod diz-nos:

Likewise, Woodman specifies a tension between the classical body and the fallen body by depicting her own image in obsessive ruined spaces, spaces once grand and classical but also now derelict, debauched. Her body, intact and beautifully - if you will - classically proportioned, appears caught in the nexus of decrepit architecture. (...) Woodman's work in Rome enunciates classicism corrupted. (RAYMOND, 2010, p. 127) ${ }^{12}$

Assim, nos tableaux vivants de Francesca, deparamo-nos com um acutilante ponto de vista alternativo ao male gaze prevalecente na História da Arte oficial que, como sabemos, era praticamente omissa, não só de obras da autoria de mulheres, mas também de uma perspetiva feminina. Nas recriações de Woodman assistimos a uma assunção corajosa da sua sexualidade e da posse plena do seu corpo. Contrariamente às figurações originais, vemos sempre nas suas re-encenações uma jovem mulher, ela própria, que torna visível e sem constrangimentos o seu avassalador desejo feminino.

\footnotetext{
12 "Woodman ao fotografar a sua própria imagem de modo obsessivo em espaços de ruínas, espaços que, porventura, terão sido grandiosos e clássicos, mas que agora são espaços abandonados e lúgubres, concretiza na sua arte fotográfica a tensão existente entre um corpo clássico e um corpo caído. O seu corpo belo e inteiro - se quisermos, de proporções clássicas - surge-nos, em grande medida, aprisionado nesta arquitetura decrépita. (...) O seu trabalho em Roma parece estudar e registar artisticamente a degradação do classicismo." (RAYMOND, 2010, p. 127).
} 


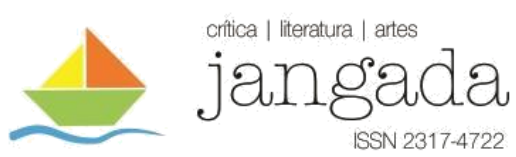

A fotografia em que Francesca glosa o célebre Nascimento de Vênus de Boticelli e se autorrepresenta envolta num papel análogo à concha do quadro do pintor italiano, segurando, porém, na mão direita um enorme búzio, óbvia metáfora de uma vulva, é neste aspeto, absolutamente exemplar. Anzieu, que se dedicou a estudar no quadro da moderna psicanálise o ego-pele, postula que a pele tem a função de envelope psíquico, o que nos ajuda a desvelar com mais propriedade a função do papel rasgado que envolve o corpo de Woodman nesta fotografia (ANZIEU, 1989). A este propósito, recorde-se o que um dos amigos de Woodman afirmou: "I always felt that she had her skin inside out" (apud WILLIS, 2010, aos 44, 34m.). ${ }^{13}$ Por outro lado, contrastando com a Vênus de Boticelli, que tapa pudicamente os seios e o sexo com as mãos, Francesca segura orgulhosamente o enorme búzio vulvar.

Porém, como em muitas outras fotografias suas, o seu rosto está cortado, não se vê. Este corte pictórico da cara, o acéphale (SOLOMON-GODEAU, 2014), que foca a atenção do recetor não no corpo nu que se vê, mas no rosto fora-de-campo, é um leitmotiv presente em todo o seu trabalho, o que, em certa medida, remete para as reconfigurações do corpo grotesco. Atente-se também na plêiade de adereços que Woodman junta organicamente ao seu próprio corpo, como se fizessem parte dele: peixes, pedras, flores, facas, serpentes, terra, folhas, papel, etc.

Aquilo que na obra de Woodman designamos por autorretrato, na verdade, não o é inteiramente. Como pode haver autorretrato sem rosto ou com o rosto irreconhecível? Poderá o olhar masculino autossatisfazer-se ao contemplar um corpo feminino, belo, jovem e nu, mas sem face e com componentes grotescos adstritos a si? Através deste recurso, Woodman faz-nos questionar o próprio modo como apreciamos uma obra de arte. Estará afinal o rosto da artista figurado nas ruínas, nos adereços e fragmentos com os quais encena tão cuidadosamente as suas obras? Riches avança a seguinte hipótese: "By always displacing herself from the imagery, Woodman's photographs accumulate to form a project of anti-self-portrait." (RICHES, 2004, p. 162$).{ }^{14}$

O seu desejo de reescrever a História da Arte é observável em muitos outros trabalhos seus (SHOR, 2014a, p. 33-49). Por exemplo, na fotografia em que recria o icónico Narciso de Caravaggio. Nele, ela posiciona-se de modo análogo ao modelo masculino original de Caravaggio, mas, em vez de olhar para um caudal de água, Francesca debruça-se sobre uma

\footnotetext{
13 "Sempre me pareceu que ela tinha a pele virada do avesso." (apud WILLIS, 2010, aos 44, 34m.)

14 "Ao colocar-se invariavelmente fora do alcance da própria fotografia, Woodman faz com que, vistas no seu conjunto, as suas fotografias configurem um projeto de anti-autorretrato." (RICHES, 2004, p. 162)
}

Jangada | nr. 14, jul/dez, 2019 | ISSN 2317-4722 52 | P á g i n a 
mesa envidraçada com uma significativa estola de raposa ao seu lado e observa o seu próprio reflexo na cortante transparência espelhada do vidro. Fotografou também um tableau vivant do celebérrimo A Leda e o Cisne de Miguel Ângelo Buonarroti. Fiel à fábula na qual se inspirou (se calhar, demasiadamente fiel para uma mentalidade puritana), o original do pintor florentino representa Leda com as pernas alteadas e o cisne, entre elas, parece penetrá-la. Na reencenação de Woodman, mais uma vez, procede-se a uma subversiva inversão. A figura feminina, que parece ser a própria Francesca, é alta, branca e longilínea, exala poder e é representada acéfala. O cisne é dócil e esta Leda woodmaniana faz-lhe uma festa, demonstrando total domínio sobre ele. Nas suas fotografias, o feminino é sempre dominante.

8. O modelo fotográfico por excelência de Francesca foi quase sempre ela própria, no entanto, existem algumas exceções, nomeadamente quando utilizou modelos masculinos. Uma dessas séries intitula-se Charlie The Model, por ser este o nome do modelo utilizado, um senhor já de alguma idade, obeso, que posa grotescamente nu para ela - a inversão hermenêutica e o desejo de reinscrição historiográfica, mais uma vez, são postos em evidência. Em tudo semelhantes às poses que ao longo da história foram sendo feitas por modelos femininos para gáudio do público receptor masculino, as posturas exibicionistas de Charlie expõem as fissuras da mediação e salientam o traço grotesco, aqui em modulação masculina.

Em algumas destas fotografias surge Woodman em posição de domínio. Charlie submisso, parece exibir-se para ela, como se fosse um prostituto. O significado desta série torna-se mais claro se a cotejarmos com outra na qual figura a própria fotógrafa, usando adereços e cenários muito semelhantes aos da série que fez com Charlie: espelhos, vidros, o lusco-fusco duma divisão abandonada. Estoutro conjunto, protagonizada somente por ela própria, intitula-se, de modo irónico, A Woman. A Mirror. A Woman is a Mirror for a Man (SCHOR; BRONFEN, 2014, p. 174).

Alguns dos tableaux vivants que Francesca re-encena fotograficamente com modelos masculinos são recriação de quadros de inspiração bíblica. Neles, uma visão pietista usualmente associada à figura feminina é transposta pela fotógrafa para o universo masculino. A dimensão fetichista emerge destas fotografias: por exemplo, quando coloca um dos seus amigos a figurar como um sofrido (e tresloucado?) Cristo, remetendo-nos para um peculiar universo de feições sadomasoquistas. Ou também quando, em cenário de crime passional, recria, num passeio de 


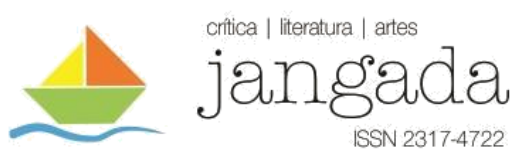

rua, a passagem bíblica em que Dalila corta o cabelo a Sansão. Estas recriações bíblicas em modulação urbano-fetichista têm também a ver com a, já assinalada, dimensão pós-apocalíptica do trabalho de Woodman.

Nos tableux vivants com modelos masculinos, quase todos eles figuram de corpo inteiro, isto é, com a cabeça e tronco bem visíveis. Existem, no entanto, algumas exceções que fogem a este padrão. Numa dessas exceções vemos somente um tronco semidesnudado com os mamilos em destaque e com a zona genital envolta em espuma. $\mathrm{O}$ nosso olhar demora algum tempo a perceber que este corpo é, na verdade, um corpo masculino (SCHOR; BRONFEN, 2014, p. 77). O seu namorado dessa época, o hoje consagrado designer Benjamim Moore, também é fotografado amiúde com a cabeça fora de campo (por vezes, nu e também acéfalo). Numa destas fotos vemo-lo sentado à mesa com Woodman. Defronte dela um prato com o desenho do rosto de Benjamim; o título desta foto é Yet another Day Alone I woke up in these White Chairs.

9. As únicas vezes em que vemos Francesca Woodman sorrir nas suas fotografias é quando utiliza modelos femininos, como as suas amigas Sloan Rankin e Sabina Mirri, que foram amplamente fotografadas por ela. Quem conheceu Woodman de perto diz que ela era exuberante, divertida e sempre muito pró-ativa. Este lado luminoso da artista está bem documentado nestas fotografias com modelos femininos e parece omisso nas outras.

Desde uma fotografia inicial, em modulação adolescente, na qual ela também figura, aqui sim, em pose, de certo modo, algo provocante e exibicionista com uma amiga, ambas vestidas com cores garridas, mostrando os seios e sorrindo, até ao tableau vivant que fez das Três Graças de Rubens, as floridas deusas da concórdia e alegria, em que três mulheres nuas com as formas do corpo muito semelhantes ao seu têm colocada à frente dos rostos uma fotografia de Woodman, como se fossem três gémeas idênticas da autora. As fotografias com modelos femininos remetem-nos assim para o que podemos designar como Utopia Feminina, conceito que remonta à idealização literário-mitológica de sociedades compostas e lideradas por mulheres, cujo referente mais transversal será porventura o mito grego das Amazonas. A este propósito, Blessing postula: “At the heart of Woodman's performances for the camera is a sense of play, of fun which may have been solitary at times, but often involved other people, specifically female friends, suggesting a kind of feminine if not feminist utopia" (BLESSING, 
2011, p. 203). ${ }^{15}$ Esta utopia em declinação feminina, em que é visível um lado feliz da artista, contrasta com o resto da sua obra.

10. Não deverá ser desprezada outra companhia sempre omnipresente em qualquer uma das centenas de fotografias que criou: a solidão. Talvez, por isso, tenha escolhido locais pósapocalípticos, como casas e fábricas abandonadas, para cenários das suas obras. São aquilo que, a partir de Lacan (LACAN, 1986), podemos designar por extimités, extimidades: o exterior não apenas enquanto espaço especular do interior do sujeito, mas o exterior íntimo (TISSERON, 2011). ${ }^{16}$

A sua obra, portanto, está pejada de restos pós-apocalípticos, de ruínas, de mobília desfeita, de animais mortos, de fruta despedaçada, de portas e janelas partidas, mas, no seu centro, figura sempre um corpo belo e fantasmático de uma mulher talentosa e jovem que, à medida que a sua própria obra avança, esconde cada vez mais o rosto e se desintegra, juntandose às ruínas que tão cuidadosamente reencenou ao longo da sua curta e intensa vida. A este propósito, Riches fala duma "narrative of erasure", uma narrativa da rasura e do apagamento (RICHES, 2004, p. 149). De certo modo, é como se o corpo da fotógrafa fosse, ao longo da sua obra, sendo lenta e inexoravelmente absorvido por esse cenário pós-apocalíptico, criado por ela própria, até à sua completa imersão nele.

Raymond infere destas encenações pós-apocalípticas e da forma como Woodman se autorrepresenta como aquilo que designa por "presentation of gaze as a force", a representação da contemplação como uma força, e especifica depois: "Woodman's self-portraits approach bodily limits. The images strategize a double presence, showing Woodman both supervising and subsumed into the architectural spaces she inhabits (RAYMOND, 2010, p. 123). ${ }^{17}$

Perfecionista, Francesca demorava horas a preparar as suas fotografias. Era meticulosa a criar os seus cenários de ruínas e pós-apocalipse. Recusando recorrer à luz artificial,

\footnotetext{
15 "No âmago da performance de Woodman ao posar para a câmara fotográfica está um agudo sentido de jogo, de prazer, que terá sido, muitas vezes, solitário, mas que também envolveu amiúde a participação de outros, em especial das suas amigas, o que, na verdade, parece consignar uma espécie de Utopia Feminina, se não mesmo feminista. (BLESSING, 2011, p. 203)

${ }^{16}$ Este conceito de "extimidade", ou seja, o exterior enquanto intimidade, é facilmente entendível se o relacionarmos, por exemplo, com o quarto onde dormimos. É essa a razão pela qual muitas pessoas, quando têm visitas, tendem a arrumar, a elidir, os sinais dessa intimidade, que se manifesta em sinais exteriores. Neste sentido, as fotografias de Woodman são sempre espaços de extimidade.

17 "Os auto-retratos de Woodman aproximam-se vertiginosamente dos limites do corpo. As imagens servem uma estratégia de dupla presentificação, mostrando-nos Woodman supervisionando-as, mas, ao mesmo tempo, submersa por elas, pelos espaços arquitetónicos que habita." (RAYMOND, 2010, p. 123)
}

Jangada | nr. 14, jul/dez, 2019 | ISSN 2317-4722

55 | Pá g in a 


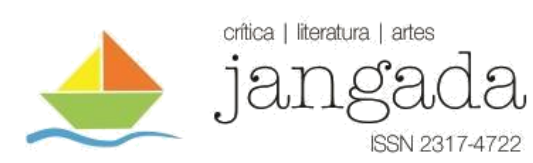

fotografava sempre com luz natural. As suas fotografias eram, por opção própria, de dimensões reduzidas e a preto e branco. Nas exposições colocava-as de modo aleatório nas paredes, ora em cima, ora em baixo. No último ano de vida, ainda tentou fazer trabalhos numa escala maior e começou a utilizar a cor, mas já não foi a tempo. A depressão com que lutou sempre instalouse nela para não mais a deixar. Nos seus derradeiros trabalhos, já não era apenas o rosto que ocultava; agora, enroscada sobre si mesma, o seu corpo nu virava-se completamente de costas para o observador. O fora-de-campo estava na sua própria carne. Será, talvez, esse o maior legado de Francesca Woodman: o registo da nossa humana e infinita solidão elevada à categoria de indizível beleza.

\section{REFERÊNCIAS BIBLIOGRÁFICAS}

ANZIEU, D. The skin ego. New Haven and London: Yale University Press, 1989.

BEAUVOIR, S. O segundo sexo: Volume II. Trad. Sérgio Milliet. $2{ }^{\text {a }}$ Edição Lisboa: Quetzal Editores, 2015. [1949]

BLESSING, J. "The geometry of time. Some notes on Francesca's Woodman's Video". In: C. Keller (Ed.), Francesca Woodman. Exhibition Catalogue (p. 203). New York: Solomon R. Guggenheim Museum, 2011.

BERGER, J. Ways of seeing. London: Pinguin Books, 1990. [1972] After the end. Representations of the post-apocalypse. Minneapolis: University of Minnesota Press, 1999.

BERNE, B. "To tell the truth". In: G. Schor; E. Bronfen (Eds.), Francesca Woodman. Works From the Sammlung Verbund (p. 89-93). Nova Iorque: D.A.P./Distributed Art Publishers, 2014. BRONFEN, E. "Leaving an imprint. Francesca Woodman's photographic tableaux vivants." In: G. Schor; E. Bronfen (Eds.), Francesca Woodman. Works From the Sammlung Verbund (p. 11-30). Nova Iorque: D.A.P./Distributed Art Publishers, 2014.

DELEUZE, G. A imagem-tempo. Cinema 2. Trad. Sousa Dias. Lisboa: Assírio \& Alvim, 2015. [1985]

HEFFERNAN, T. Post-apocalyptic culture. Modernism, post modernism and the twentiethcentury novel. Toronto: University of Toronto Press, 2008.

LACAN, J. Seminário. Livro 11. Os quatro conceitos fundamentais da psicanálise. Rio de Janeiro: Zahar Editora, 1988. [1964]

PIPPIN, T. Apocalyptic bodies. The biblical end of the world in text and images. London: Routledge, 1999.

RAYMOND, C. Francesca Woodman and the kantian Sublime. New York: Routledge, 2010. . Francesca Woodman's dark gaze. The diazotypes and other late works. New York: Routledge, 2016. 
RICHES, H. K. Skin, surface and subjectivity. The self-representational photography of Francesca Woodman. Tese de doutoramento, University College London. Londres: Reino Unido, 2004. Retirado de: http://discovery.ucl.ac.uk/1383222/1/405969.pdf

SCHOR, G.; BRONFEN, E. (Eds.) Francesca Woodman. Works from the Sammlung Verbund. Nova Iorque: D.A.P./Distributed Art Publishers, 2014.

SCHOR, G. "Introductory remarks and acknowledgements". In: G. Schor; E. Bronfen (Eds.), Francesca Woodman. Works From the Sammlung Verbund (p. 7-9). Nova Iorque: D.A.P./Distributed Art Publishers, 2014.

"Props as metaphors - arranged by Francesca Woodman". In: G. Schor; E. Bronfen

(Eds.), Francesca Woodman. Works From the Sammlung Verbund (p. 33-49). Austria: Sammlung Verbund, 2014a.

SOLOMON-GODEAU, A. "Just like a woman". In: A. Gabhart; R: W. Krauss (Eds), Francesca Woodman Photographic Work (14-35). Wellesley: Wellesley College Museum and Hunter College Art Gallery, 1986. Retirado de: https://www.galeriewinter.at/en/artists/francesca-woodman/abigail-solomon-godeau-just-likea-woman/

. "Body double". In G. Schor; E. Bronfen (Eds.), Francesca Woodman. Works From the Sammlung Verbund (p. 73-87). Nova Iorque: D.A.P./Distributed Art Publishers, 2014.

TISSERON, S. "Intimité et extimité". Communications, Volume 88, No 1, 83-91. 2011.

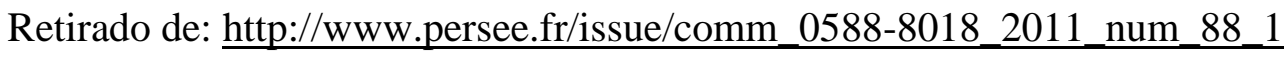

WOODMAN, F. Some disordered interior geometries. Philadelphia: Synapse, 1981.

\section{REFERÊNCIAS FÍLMICAS E VIDEOGRÁFICAS}

COELHO, E. P. Portugalmente III. Lisboa: RTP 2, 1999. Retirado de: https://arquivos.rtp.pt/conteudos/francesca woodman/\#sthash.TnmVOYTy.RSVbYvMC.dpbs WILLIS, C. S. The Woodmans. C. Scott Films, 2010. Retirado de: https://www.youtube.com/watch? $\mathrm{v}=5 \mathrm{zqNUdtCwkU}$

WOODMAN, F. Francesca Woodman's video-work, 1976-1981. Retirado de: https://www.youtube.com/watch?v=7-QdeKDkXqE 